\title{
Study on Problems and Countermeasures in Beijing Wind Energy Power Generation Connected to Grid
}

\author{
Yi-Ming JIANG ${ }^{1, a}$, Xiao-Hong ZHANG ${ }^{1, b,{ }^{*}}$, Si-Wen $\mathrm{HU}^{1, \mathrm{c}}$ and Yan-Ling $\mathrm{LI}^{1, \mathrm{~d}}$ \\ ${ }^{1}$ Beijing Institute of Petrochemical Technology,19\#,Qingyuan North Road, Daxing District, Beijing, \\ China \\ a1475776513@qq.com, 'leadship999@sohu.com, ’hsw@163.com, dliyanling@bipt.edu.cn.
}

Keywords: Wind energy, wind power generation, connected to grid.

\begin{abstract}
In this paper, the problems in the Beijing wind power Generation connected to grid are studied, and the interaction between wind power and power grid are further studied after the large-scale wind power is integrated into the power grid. This paper briefly analyzes the problems between wind power system and public power grid and puts forward some suggestions, which are of great importance to guarantee the safety and stability of wind power system and public power grid and improve the operation reliability. The study on wind power generation connected to grid is beneficial to the sustainable development of Beijing economy and society, it can play a certain role in the future development of wind power, and it is of great significance to improve the living standard of the residents.
\end{abstract}

\section{Overview}

With the rapid development of modern society, energy consumption is increasing. Wind energy is a clean energy source, which is pollution-free and renewable. It is generally valued for its advantages of cleanliness and safety.

This paper takes the current situation of wind power generation connected to grid in Beijing as the main research object, and takes some problems in wind power generation as the breakthrough point, and puts forward corresponding solutions.It is hoped that this study will promote the long-term stable and rapid development of wind power in Beijing and provide references for wind power generation in other regions.

Wind energy is a kind of abundant green energy, which is clean, safe, renewable and pollution-free. It is currently the world's most promising new energy source for large-scale development and commercialization.China has also been studying and improving the technology of wind energy utilization, which has promoted the improvement of wind energy technology and made great contributions to reducing greenhouse gas emissions, protecting the environment and promoting sustainable economic and social development.

\section{Status of Beijing Wind Power Generation Connected to Grid}

For a big city like Beijing with a resident population of more than 20 million, the annual average power consumption exceeds 100 billion $\mathrm{kWh}$. The demand for power is great. It is hoped that we will find a rapid and long-term development path for Beijing's wind power generation through the study.

\section{The Origin of Beijing Wind Power Generation}

The development of wind power in the world's industrial history is short-lived, but its rapid pace of development and its great technological progress are amazing. China's wind power is developing very rapidly, and its total installed capacity has increased from $4200 \mathrm{~kW}$ at the end of 1989 to $188 \mathrm{GW}$ in 2017, which indicates that China's wind power generation has entered the forefront of the world.

China promotes the sustainable development of wind energy through various preferential policies and incentive mechanisms, such as franchise policy, benchmark price policy, preferential tax policies, CDM clean development mechanism, and cost sharing policy, full acquisition policy and so on. The 
survey found that $70 \%$ of the wind resources in the city are located in the northwest of Yanqing County, with an average annual wind speed of 10 meters per second and average wind speed of 7.0 meters per second at 70 meters. It has good conditions for building wind power plants.

At the end of 2007, Guanting Wind Power Plant, located in Yanqing County, Beijing, was officially connected to the grid, and Beijing officially entered the era of wind energy development.All the electricity generated in the first phase of the project goes into Beijing's urban power grid, saving 20 million cubic meters of natural gas annually, reducing carbon dioxide emissions by 100,000 tons, sulfur dioxide emissions by 782 tons, nitrogen oxides by 444 tons, and carbon dioxide emissions by 11 tons. The installed capacity of the second phase of the wind power plant reached 100,000 kilowatts. In 2016, 33 sets of 1.50 megawatts wind turbines were installed and connected to the grid for power generation.The fourth to eighth phase of Guanting Wind Power Plant is also under planning and construction. The installed capacity of Beijing's wind power generation will increase by 450,000 kw in 2020, and the total capacity will reach $650,000 \mathrm{kw}$.

\section{Status of Wind Power Price}

At present, the average electricity price for wind power has dropped from about 1 yuan per kWh to 0.43 yuan to 0.78 yuan per $\mathrm{kWh}$.However, the on-grid tariff of wind power is still higher than the on-grid price of coal and hydro-power, and the price difference is relatively large, as shown in Fig1.

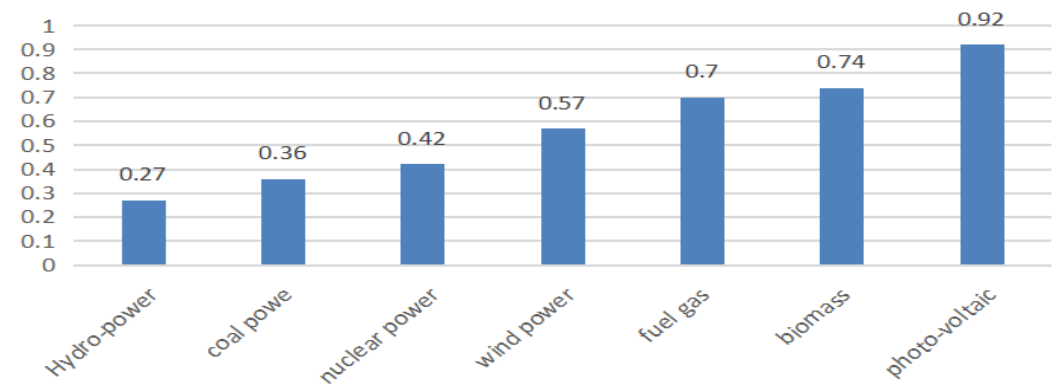

Fig. 1 The comparison of on-grid tariffs of different types of energy generation

\section{Source: 2016 National Electricity Price Supervision Bulletin}

Due to the differences in the richness of wind energy resources and development conditions in different regions, the prices of wind power in different regions are not the same, and there is even a big gap.In a word, the average electricity price of wind power is still higher than the on-grid price of coal power of 0.21 yuan / kWh.

\section{Problems in the Development of Wind Power in Beijing}

Since the 1980s, wind power generation experiments and demonstrations have been gradually carried out in China and gradually popularized and applied. Beijing began building its first wind power plant in 2005.As a potential green alternative energy source, wind energy has developed rapidly. However, compared with the development speed of wind power in the world, it is still far behind.

\section{Reliability Issues}

The distribution of wind energy resources has limitations.Most of wind power plants are built in places such as mountainous areas or wilderness where wind requirements are met. It belongs to the weakest part of the power grid and the network structure is relatively weak. When the wind power plant is connected to the grid, it will inevitably affect the quality and stability of the grid voltage.The uncontrollable and uncontrollable nature of wind power generation may lead to the instability of wind power generation.

\section{Price Issues}

With the development of technology and the increase of people's cognition, wind power as a clean energy has been paid more and more attention.However, the development of Beijing's wind power is 
still at the stage of investment by the government. There are both technical and policy issues among them.However, the core issue is the price of wind power on-grid.The high price of wind power on-grid electricity leads to a higher retail price than other energy types, which leads to a low utilization rate of wind power.

Trial Measures for the Management of Price and Cost Sharing of Renewable Energy Power Generation clarifies the pricing method for on-grid tariffs, and clarifies the management methods for on-grid tariffs that exceed some users' apportioning principles and the level of apportionment and collection of expenditures. Although the wind power pricing system has undergone several changes, the calculation method is still measured according to the principle of cost plus reasonable profit. The core is determined by the power generation cost, tax and reasonable after-tax profit of the wind power plant. The calculation formula is: on-grid electricity price $=$ power generation cost $+\operatorname{tax}+$ after-tax profit.

The price of wind power is mainly affected by resource conditions, system cost, national policies and market conditions.

It can be seen from the above factors that, due to the restrictions of resources, technology and other conditions, the amount of electricity generated will directly influence the price of wind power. The higher the number of generating hours, the lower the price of wind power will be. In other words, the richness of wind energy resources in the region where wind power plants are located has a great impact on the formation of wind power prices in the region.Beijing's wind power generation has not yet entered the mature stage, generating capacity has not yet entered an ideal state, resulting in high wind power costs and high electricity prices.

Another important factor influencing wind power price is the tax and financing conditions.As shown in Table1, from the perspective of economic analysis, the excessive burden of taxes and repayment is also the reason for the high wind power price. $27 \%$ of wind power on-grid tariffs are used to pay taxes, which is about $8 \%$ higher than coal power; profits used for repayment of loans account for $8.6 \%$ of on-grid electricity prices, and $7.3 \%$ more than coal power.In addition, the tax paid by wind power generation is $0.17 \mathrm{yuan} / \mathrm{kWh}$, while the coal power generation is only 0.07 yuan/kWh, and the wind power tax burden is almost three times that of coal power.

Table 1 Comparison of wind power and coal-electricity on-grid price (\%)

\begin{tabular}{|c|c|c|}
\hline & Wind power generation & Coal power generation \\
\hline Average on-grid price & 100.00 & 100.00 \\
\hline cost charges & 49.7 & 64.4 \\
\hline Tax & 27.00 & 18.96 \\
\hline Income tax & 11.50 & 8.16 \\
\hline Profit after tax & 23.30 & 16.57 \\
\hline Repayment of profits & 8.60 & 1.18 \\
\hline Shareholder profit & 10.90 & 12.90 \\
\hline Public funds and public welfare funds & 3.90 & 2.49 \\
\hline
\end{tabular}

Source: Wind Power Incentive Policy Research, China energy, 2007, (11)

Investment in wind power plants is very risky, and financing conditions are harsh.Investors lack preferential long-term loan funds. It is difficult to start up. There is high pressure to repay loans.At present, the repayment period of thermal power is 13 to 18 years, while that of wind power is only 7 years, and that of hydro power is 18 to 25 years.It can be seen that after the completion of the wind power project, the loan repayment pressure is great and the financial cost is high, which leads to the high price of wind power and reduces the market competitiveness of wind power.

\section{Policy Issues}

In the development of wind power in recent years, apart from the existing problems in the on-grid price of wind power in Beijing, the policy problems are also very obvious. Under the encouragement of major national policies, the problems of wind power development in Beijing are mainly embodied 
in the following aspects. First, the lack of wind power development goals and feasible strategic planning.Second, the lack of effective economic incentive policies and strong institutional guarantee.Third, the lack of policy measures to encourage the localization of wind turbines.

\section{Definition of Development Goals is not Clear}

Relevant national departments like the State Planning Commission, the State Economic and Trade Commission, the Ministry of Science and Technology, and the State Power Corporation have formulated a series of development plans or development programs for the development of wind power generation, which has played an active leading role in the development of Beijing wind power generation.However, at present, the proportion of wind power in the energy structure is not clearly defined.

\section{Preferential Policies are not Clear}

The government has introduced a series of preferential policies to promote the development of wind power.For example, wind power prices are subject to repayment of principal and interest plus reasonable profits.[1] however, there are no details.Wind power investors face many difficulties in understanding and operating.In addition to the power sector and its subordinate units, there are very few commercial investments and independent power developers.Market reform may be an effective way to break the original system and mechanism of power market.

\section{Technology Issues}

The overall technology of wind power generation will restrict the development of wind power, so it is necessary to strengthen the research on the whole technology of wind power, so as to promote the development of Beijing wind power industry to provide good hardware facilities and lay a solid material base.

The stability of wind energy comes from the natural wind speed, and the natural wind speed has instability.Therefore, the stability of the output power of wind turbines is a core problem of wind power generation technology.So far, researchers have proposed a variety of ways to improve the quality of wind power generation.[2]It is feasible to use energy storage technology or some coordination devices to improve the adverse effects of wind power on power grids.

Under the premise that the energy storage technology has not been fully applied, the power generation and load of the power grid is a dynamic balance.The output of a wind turbine is determined by the characteristics of the unit and the speed of the wind.The variation of wind speed has the characteristics of uncertainty and intermittent.The way to offset this intermittent power generation and supply balance shock is to have sufficient regulation capacity and regulation speed to compensate for this impact.A large amount of wind power connected to the grid requires that other power supplies in the network must add more adjustment capacity and more flexible adjustment speed.China also needs to strengthen research and development of wind power facilities and strengthen macro-control.[3]

\section{Countermeasures for Solving the Problem of Wind Power Generation Connected To Grid in Beijing}

\section{Create a Stable Market for Wind Power Generation}

In order for wind power generation to achieve better development in Beijing, it should create a stable market for domestic wind turbines.Now, wind power generation in Beijing is just getting started, and it is necessary to develop a series of plans to promote the development of wind power.For example, after the completion of the fourth phase of the Guanting Wind Farm project, the development of other wind power projects should continue. In addition, ensure that the electricity generated by the wind power plant can be fully input into the power grid through the support of the relevant government, avoiding the wind and power cuts, and making the wind power more widely used. Is it possible to consider building some equipment capable of storing electricity near the wind power plant to provide a stable market demand for the Beijing wind power generation industry. 


\section{Improving the On-grid Tariff Policy for Wind Power Generation}

For a long time in the past, local governments in China have set different standards for the on-grid price of wind power generation, which has caused a certain degree of imbalance in wind power prices.The National Development and Reform Commission issued the "Notice on Improving the On-grid Electricity Price Policy for Wind Power Generation". During the 13th Five-Year Plan period, the "Beijing Energy Development Plan for the 13th Five-Year Plan" was issued to further regulate wind power price management.The result of the onshore wind power on-grid tariff adjustment is to divide the country into four types of resource zones, and reduce the on-grid tariff of wind power benchmarks in the first, second and third resource zones by 2 cents per $\mathrm{kWh}$. The on-grid tariffs for new onshore wind energy projects are 0.49 yuan per $\mathrm{kWh}, 0.52$ yuan per $\mathrm{kWh}$ and 0.56 yuan per $\mathrm{kWh}$ respectively.The Beijing area is the fourth type of wind energy resource zone, and the on-grid tariff of wind power benchmarks is currently maintained at 0.57 yuan per kWh, which is also the highest standard for nationwide wind power on-grid tariffs.

At present, policy support and incentives remain an important support for wind power generation.According to the current regulations, the excess electricity price for wind power generation should be apportioned. However, the power sector has been transformed into a corporate system, and as a commercial company, the power companies cannot and are not obligated to bear the excess electricity price for wind power.[4] Therefore, it is necessary to make further provisions on the scope and methods of apportionment.The part of the wind power on-grid electricity price that is higher than the average electricity price of the grid should be shared by the government and the whole society. It is reasonable and fair for the whole society to bear the part of the price of wind power that is higher than the average price of power grid.

\section{Wind Energy Developers’ Investment Preferential Policy}

In addition to costs, there are many other factors that affect electricity prices. Wind power prices have always been determined according to cost + reasonable profit, namely: on-grid electricity price $=$ power generation cost + tax + after-tax profit.[5]Wind power on-grid electricity price is about 0.5 yuan / kWh, resulting in high cost of wind power generation.Wind power investors are less motivated because they cannot make profits.Government departments should improve the compensation mechanism for wind turbines, formulate targeted incentive prices, and encourage investors to invest.

At the same time, the government should choose a wind power generation company with rich management experience to form a wind power generation developer team. The wind power generation developer team provides systematic services for resource evaluation, site selection, wind power plant design, equipment selection, equipment procurement equipment installation and commissioning and wind power plant operation management of new wind power projects, reducing transaction costs and operation management costs of wind power generation development, thereby reducing the overall cost of wind energy power generation.In addition, enhance the competitiveness of wind power generation and expand the market share of wind power in Beijing, thus mobilizing the investment enthusiasm of wind power investors.

\section{Establishing a Scientific Wind Power Operation Mechanism}

At present, wind power enterprises are mainly composed of direct enterprises or wholly owned subsidiaries of electric power companies, shareholding companies controlled by electric power companies and enterprises closely connected with electric power companies. Only a few of them are completely independent wind power enterprises. The construction of wind power plant is actually a government action. Commercial operations cannot be formed.The development of the wind power market still depends on government policy incentives or subsidies, international grants or loans.At presents, it still needs policy support from the Beijing municipal government.After the development of wind power in the future is on the right track, it will gradually reduce its dependence on government behavior, and rely on the improvement of its own technology and economy, and gradually reduce power generation costs and on-grid tariffs, and finally realize commercial operation and industrialization. 
In addition, we should not only encourage and guide the development of the clean energy industry chain in Beijing, but also increase the technological breakthrough and investment in the key technologies of wind power generation, and speed up the localization rate and technical transformation of wind power equipment so as to reduce costs and improve the availability and efficiency of domestic wind turbines.At the same time, by drawing on the construction of operational mechanisms in other regions, combined with the actual situation of the Beijing region itself, a reasonable operational mechanism suitable for Beijing can be established, so as to enhance the competitiveness of wind power generation in the market.

\section{Further Enhance Wind Power Technology}

From the perspective of technology, the current technical obstacles restricting the development of wind power are mainly concentrated in the two major areas of large-scale energy storage and smart grid. It requires the joint efforts of our government, enterprises, scientific research institutions and the community to increase investment and accelerate research and development, form available technological achievements and seize the technical commanding heights.Thus, although Beijing was not the first to use wind power, it can be the first turning point for the comprehensive development of wind power.

First, study large-scale storage technology. Wind power generation is different from fossil energy generation.High volatility is the bottleneck of wind power generation, and large-scale energy conversion technology and energy storage technology are the solutions. The most common method of energy storage is a pumped storage power station. It mainly uses the electric energy output from the wind energy generator to store water in the middle of the night when the wind is strong and the user demand is low; the turbine is used to generate electricity when electricity is needed. Beijing Guanting Wind Power Plant is located beside the Guanting Reservoir, which will not only be more conducive to the development of wind power, but also to drive hydro-power generation.Battery energy storage technology is also a key field to be paid attention to. It can reduce air pollution caused by exhaust emissions.In addition, the technology of hydrogen production through water electrolysis uses the surplus wind energy to convert into hydrogen gas for storage, which is also a very effective method of energy storage.

Second, accelerate the creation of a "smart" power grid.The "smart" power grid is an integrated and coordinated network system. The "smart" power grid takes communication information as a platform to intelligently control, coordinate power generation, transmission, substation, power distribution, power consumption, and dispatching, covering all voltage levels, and achieving the highly integration of "information flow, service flow, and power flow" to create a modern grid with unified interconnection and interaction.[6]

Third, wind power generation can be integrated with other renewable energy sources. For example, Changping, Qinghuiling scenery complementary power generation project.It uses solar array and wind turbines (converting AC to DC) to store the emitted energy into the battery pack. When the user needs to use electricity, the inverter converts the DC power stored in the battery pack into AC power and sends it to the user load through the power transmission line.Wind turbines and solar cell array are used to generate electricity together, which complement each other and promote the development of Beijing's electric power industry.[7]

\section{Implementing Wind Power Development Policy}

In order to better develop wind power in Beijing, the Beijing municipal government has formulated various policies to ensure wind power generation, to further optimize the clean energy policy.Strict implementation of the "Renewable Energy Law" should also refer to the subsidy policy of the wind power industry, which is developing rapidly in wind power, and introduce specific wind power price subsidy measures and implement them.

At the same time, the power grid company should be required to promise to acquire all the electricity generated by wind power in the grid-connected contract in the form of a contract. Once promised, the power grid company cannot refuse to buy wind power. For example, when the sales 
price is adjusted comprehensively, the sales price of wind power generation is allowed to be separately accounted for, so as not to cause economic losses to the grid company.[8]

\section{Conclusions}

The history of wind power development in China has only been more than 20 years, but it has achieved remarkable results.In the process of development, the problem is inevitable.Fortunately, through the formal implementation of the Renewable Energy Law, the government and the people have gradually deepened their understanding of wind power, and the development of the wind power generation industry is facing a broader development space. The wind power industry and related scientific research institutions should seize this opportunity to make feasible plans for the overall development of wind power, and make the wind power popular and supply to the people for use.

\section{Acknowledgement}

This research was supported by the Beijing the Great Wall scholar training program(CIT\&TCD20180314) and BIPT Breeding Project of Outstanding Academic Leaders (BIPT-BPOAL-2015)

\section{References}

[1] Zhao Zhenyu, Fan Leilei. Renewable energy regulations, policy analysis and its impact on power generation structure [J]. Renewable energy, 2010, 28(4):5-9.

[2] Liu wanfu. Research on marketing operation strategy of wind power based on public goods supply [D]. North China electric power university (Beijing),2008.

[3] Sun Lei, Wang Chong. Research on Maximum Power Control Strategy of Permanent Magnet Direct Drive Wind Turbine[J]. Digital Fashion,2014(3).

[4] ZhaoJiaxi. Research on the competitiveness of wind power equipment manufacturing enterprises [D]. North China Electric Power University (Beijing),2011.

[5] Li Kai. Problems and countermeasures of wind power generation in China[J].Technology Wind2011(15):228-228.

[6] Anonymous.Transforming the way of power development to meet the challenges of low-carbon technology - representatives of the two associations discuss the transformation of power development[J]. China Water Power \& Electrification, 2010(3):49-52.

[7] TuChanggeng. Smart Grid and Hydropower Generation [J]. Hydropower and New Energy,, 2011(2):63-68.

[8] China-nengyuan.com The National Development and Reform Commission and the National Energy Administration officially promulgated the "13th Five-Year Plan for Power Development" [J]. China National Nuclear, 2016(11). 